\title{
Educação Ambiental e Ecoturismo: uma proposta para Nova Iguaçu $(\mathbf{R J})$
}

\author{
Environmental Education and Ecotourism: a proposal for Nova Iguaçu (RJ)
}

\author{
Marcia Luiza Figueiredo Machado, Nadja Maria Castilho da Costa
}

\section{RESUMO}

A construção de uma proposta integradora para as ações de Educação Ambiental e Ecoturismo têm grande fonte de contribuição na Geografia. O objetivo desta pesquisa centra-se na produção de proposições para as escolas da Rede Municipal de Educação de Nova Iguaçu (RJ), situadas na área de influência direta do Parque Natural Municipal de Nova Iguaçu. A metodologia constituiu-se de levantamento bibliográfico, acompanhamento de atividades pedagógicas, trabalho de campo, entrevista e aplicação de questionários. O prognóstico realizado será um novo referencial para o tema transversal Meio Ambiente. Inserir o ecoturismo, a partir das ações de Educação Ambiental, e como ele pode ser veículo da conservação ambiental, da inclusão social e da melhoria da qualidade de vida das populações locais, ainda é um desafio que será enfrentado por cidades como Nova Iguaçu, com forte potencial e vocação para atividade ecoturística.

PALAVRAS-CHAVE: Educação Ambiental; Ecoturismo; Parque Natural Municipal de Nova Iguacu.

\begin{abstract}
ABSTRAT
The construction of an integrated proposal for the actions of environmental education and ecotourism are great source of contribution to geography. This research focuses on the production of proposals for the schools of the Municipal Education Nova Iguaçu (RJ, Brazil), located in the area of direct influence of the Municipal Natural Park of Nova Iguaçu. The methodology consisted of literature review, monitoring of educational activities, field work, interviews and questionnaires. The prognosis subsidize a new benchmark for cross-cutting issue Environment. Insert ecotourism, from the actions of environmental education, and how it can be a vehicle for environmental conservation, social inclusion and improving the quality of life of local populations, is still a challenge that we face in cities like Nova Iguaçu, with strong potential and vocation for ecotourism activity.
\end{abstract}

KEYWORDS: Environmental Education; Ecotourism; Municipal Natural Park Nova Iguaçu. 


\section{Introdução}

O ambiente é o pano de fundo, o palco de sobrevivência da vida sobre o qual se mantém e se estabelecem as relações socioambientais e sobre ele sempre repousaram preocupações diversas, porém, desarticuladas e não sistematizadas. Este quadro somente foi revertido nos anos de 1960, quando o debate científico aliado aos instrumentos tecnológicos impulsionou as pesquisas ambientais. Detectada e propagada a urgência do tratamento da temática, uma verdadeira crise socioambiental se instaurou em âmbito mundial, e no Brasil, o movimento ecológico emergiu na década de 1970 (DIAS, 2000).

Em 1999, a educação formal foi chamada a se integrar às preocupações acerca do ambiente, proporcionando aos indivíduos a construção de valores e a aquisição de conhecimentos, atitudes e habilidades voltadas para participação responsável na gestão ambiental. Neste contexto, reconhece-se no campo da educação ambiental, a potencialidade de promover a reflexão e a problematização das relações entre a sociedade e o ambiente e de influir sobre a sensibilidade e a consciência dos indivíduos e coletividades para as mudanças necessárias.

Os Parâmetros Curriculares Nacionais ( $\mathrm{PCN}$ ) tornaram a temática ambiental transdisciplinar, o que significou colocá-la à disposição de todas as disciplinas que integram o currículo, para que cada uma pudesse fornecer a sua contribuição científica. Neste sentido, algumas questões que trazem no seu bojo a preocupação com o meio ambiente passaram a ser importantes e passíveis de serem abordadas em sala de aula, a exemplo da análise das principais ações transformadoras do ambiente, dentre elas o turismo.

Em estados como o Rio de Janeiro, que apresenta um quadro natural exuberante, grande parte da visitação e do lazer é efetuada na natureza, principalmente no interior de Unidades de Conservação. Foi desta forma que, alicerçada em experiência pessoal, procurou-se trabalhar, na presente investigação, na compreensão da educação ambiental associada ao ecoturismo, tomando como base a realidade específica do Município de Nova Iguaçu, com riquíssimo Patrimônio Ambiental e, por conseguinte, com elevado potencial para as práticas de turismo na natureza, particularmente o ecoturismo. O trabalho tem como foco principal as escolas do entorno do Parque Natural Municipal de Nova Iguaçu, localizado na região metropolitana do Rio de Janeiro.

Inserir nas escolas o conhecimento sobre o ecoturismo, a partir das ações de educação ambiental, e como ele pode ser veículo de conservação ambiental, de inclusão social e da melhoria da qualidade de vida das populações locais ainda é um desafio que os empreendedores e educadores deverão enfrentar nos próximos anos, em cidades como Nova Iguaçu, com poucas opções de lazer e forte potencial para o desenvolvimento dessa atividade, na natureza. 


\section{Educação Ambiental e Ecoturismo: uma interação viável no ensino formal}

Diante de inúmeros problemas ambientais (desmatamento, poluição, escassez de água, etc.), consequentes do modelo de desenvolvimento econômico adotado por vários paises, pessoas e instituições começaram a perceber que o ambiente não suportaria a intensidade da agressão humana. Iniciou-se, então, um processo de mobilização em torno da questão ambiental, o qual se expandiu e se consolidou por meio da divulgação de estudos científicos, da publicação de livros sobre o tema e da realização de conferências que, entre outras questões, alertaram a humanidade de que a degradação do ambiente comprometeria a manutenção da vida na Terra.

Dessa forma, este cenário também ficou marcado pelos grandes debates em torno das estratégicas para ampliar e consolidar os espaços institucionais em favor da educação ambiental: dever-se-ia inserir ou não a educação ambiental como disciplina singular dentro do currículo escolar de ensino fundamental? Algumas experiências nesse sentido foram vividas em diferentes pontos do Brasil. Apesar disso, as discussões apontavam para a necessidade de enfatizar o caráter interdisciplinar da temática ambiental, não sendo muito favoráveis à criação da educação ambiental como disciplina específica.

Na década de 1990, o discurso sobre a disciplinarização da educação ambiental ganha um desfecho final, consolidando a posição do Conselho Federal de Educação de 1987, de não constituir a educação ambiental como disciplina específica, tendo adquirido, em sua formulação final, o caráter de Tema Transversal, apresentado pelos Parâmetros Curriculares Nacionais (PCNs).

Os PCNs são documentos elaborados pelo Ministério da Educação e Cultura (MEC) que servem como referencial e apoio às discussões e ao desenvolvimento do projeto educativo de cada escola brasileira, à reflexão sobre a prática pedagógica coerente, ao planejamento das aulas, à análise e seleção de materiais didáticos e de recursos tecnológicos, na formação e atualização do profissional da Educação. É importante ressaltar ainda que eles foram elaborados procurando, de um lado, respeitar diversidades regionais, culturais, políticas existentes no país e, de outro, considerar a necessidade de construir referencias nacionais comuns ao processo ensino aprendizagem em todas as regiões brasileiras.

Em vários e importantes documentos enfatiza-se a importância da educação ambiental, entre outros motivos, pela sua relação como exercício da cidadania, o que demonstra o seu compromisso original com a formação da cultura democrática; e pelo aguçar do sentimento de pertencimento a uma coletividade, como algo que perpassa e ultrapassa o universo individual (LEONARDI, 1997).

Com o referencial dos PCNs, em especial, do tema transversal Meio Ambiente, a escola, os conteúdos e o papel do professor e dos alunos são colocados em uma nova situação, não apenas relacionada com o conhecimento, mas sim com o uso que fazemos dele e sua importância para a nossa participação política cotidiana. 
A temática ambiental envolve questões relacionadas tanto à proteção e conservação do ambiente natural, quanto à melhoria da qualidade de vida das comunidades. Nesta perspectiva, são estudados os aspectos físicos, biológicos, geográficos, as diversas interações do homem com a natureza através das relações sociais, do trabaIho, da ciência, da arte, da tecnologia, etc. O estudo de tais questões exige o conhecimento dos conteúdos das disciplinas do currículo escolar, como também, as discussões dos valores existentes na interação homem e natureza. A temática ambiental está desta forma impregnada no conjunto de disciplinas curriculares, ocupando assim uma posição de transversalidade (BRASIL, 1998)

Dentro dessa proposta, cada acontecimento do cotidiano estará relacionado à nova mentalidade de consciência ambiental, pois a complexidade ambiental emerge do diálogo entre saberes e conhecimentos. Este fato nos leva a uma reflexão, por exemplo, de como o professor de Geografia conduzirá o seu planejamento, tornando-o flexível às situações existentes na própria comunidade: os resíduos sólidos, o esgoto, o abastecimento de água, o deslocamento de um lugar para o outro, o papel das tecnologias na construção do espaço, dentre outras questões deverão estar relacionadas, com a forma de interpretar, analisar, calcular, dissertar e refletir sobre o ambiente. Um problema individual passa a ser um problema coletivo, e o cidadão passa a exercer a função de um agente ambiental, tornando-se responsável pelas transformações do espaço e dos lugares, e exigindo que, tanto as pequenas infrações quanto as grandes catástrofes sejam evitadas.

A intenção dos professores de Geografia engajados nas ações de Educação Ambiental é, sem dúvida, buscar fazer da Geografia uma disciplina interessante, contextualizada às questões ambientais, à vida, na qual se possa compreender o espaço construído pela sociedade, como o resultado da adesão entre o espaço natural e o espaço transformado efetivamente pelo homem e, não somente aos dados e informações dos livros didáticos que pareçam distantes da realidade.

O professor de Geografia, ao incluir no planejamento a questão ambiental, não pode se omitir da discussão sobre a participação coletiva nas ações de Educação Ambiental, tendo em vista o panorama claro dos problemas, à princípio de ordem local e, posteriormente, de ordem regional e global. A compreensão e explicação desses problemas são de fundamental importância na construção da prática pedagógica desses profissionais, pois partindo do lugar em que se vive é mais fácil compreender os fenômenos ocorridos e, assim, tomar decisões e intervir criticamente no ambiente.

Vale à pena destacar a importância do ensino da Geografia para as práticas ecoturísticas, pois através da construção dos conceitos de espaço e de paisagem, por exemplo, é permitido que o aluno tenha outro olhar para a natureza contemplada e uma sensível/consciente postura durante essas práticas, além de aguçar "sua percepção sensorial sobre os recursos ambientais (o meio biótico e os componentes do meio físico) existentes" (COSTA; COSTA, 2008, p.111).

A propósito, a Educação Ambiental e o ecoturismo envolvem forte relação entre paisagem e lugar, que são, por natureza, objetos de estudo da Geografia. Ainda, "a paisagem é um recurso para a economia do turismo, sendo a imagem que dela criam a mercadoria vendida para o visitante" (COSTA; COSTA, 2008, p.121). 
Cabe ressaltar também que o conceito de paisagem, como categoria de análise geográfica nas ações de EA e ecoturismo, tem um caráter especifico, distinto do utilizado pelo senso comum ou por outros campos do conhecimento.

Pois, segundo os PCN (BRASIL, 1998, p.112):

\begin{abstract}
é na paisagem que estão manifestadas e inscritas uma reunião de tempos desiguais, uma combinação de espaços geográficos. (...) Ela é definida como uma unidade visível que possui uma identidade visual, caracterizada por fatores de ordem social, cultural e natural, contendo espaços e tempos distintos; o passado e o presente. A paisagem é o velho no novo e o novo no velho.
\end{abstract}

$\mathrm{Na}$ realidade, é importante considerar o ecoturismo, segmento do turismo que cresce cada vez mais, como uma alternativa aos problemas ambientais, pois busca agregar valores à prática do turismo; proporciona ampla oportunidade sociocultural e econômica para as classes menos favorecidas; é uma das melhores alternativas para a conservação ambiental e para a inclusão das populações que se encontram em ambientes e ecossistemas frágeis, como as áreas naturais protegidas e seu entorno. Nesta perspectiva, quando é praticado corretamente, gera oportunidades de emprego, renda, sustentabilidade e consciência ambiental.

Coriolano (2003, p.124) afirma que "o ecoturismo é uma modalidade de turismo dirigido a grupos especiais, evitando grandes concentrações e, sobretudo, integrando o turismo como atividade econômico-social ao meio ambiente natural".

Confirmando essa tendência, uma das causas dos sérios danos ao ambiente, depredação do Patrimônio Histórico e Cultural ao redor de uma Unidade de Conservação é o fato de que, normalmente, o visitante e/ou morador do entorno não está preocupado com a conservação do bem natural e/ ou cultural por não obter conhecimento suficiente para compreender a sua relevância. Isto o que destaca a importância da Educação Ambiental aliada ao Ecoturismo como uma ferramenta essencial para a garantia da sustentabilidade e gestão de uma Unidade de Conservação. De acordo com Geerdink e Neiman (2010, p. 79):

o ecoturismo parece ser uma ótima oportunidade de discussão dos valores da sociedade para o meio ambiente, uma vez que, se bem trabalhadas as percepções e construídas novas representações, tendo a natureza como inspiradora, a educação ambiental pode ser transformadora no sentido da sustentabilidade.

Portanto, propomo-nos a construção de proposições integradoras de Educação Ambiental e Ecoturismo, e escolhemos o exemplo das escolas da Rede Municipal de Nova Iguaçu, localizadas na área de influencia do Parque Natural Municipal de Nova Iguaçu - PNMNI para ilustrar esta prerrogativa. 


\section{Propostas Integradoras entre Ecoturismo e Educação Ambiental nas Escolas da Área de Influência do Parque Natural Municipal de Nova Iguaçu (PNMNI)}

\section{O Parque Natural Municipal de Nova Iguaçu (PNMNI)}

O PNMNI (Figuras 1 e 2) faz parte da Área de Proteção Ambiental (APA) do Gericinó-Mendanha, considerada Reserva da Biosfera pela UNESCO, em 1996. Em 5 de junho de 1998, o PNMNI passou a ser considerado uma Unidade de Conservação de Proteção Integral, pelo Decreto no 6001, numa área de 10.500 hectares entre as coordenadas $7485 / 7477 \mathrm{~km}$ e $650 / 658 \mathrm{~km}$. Sua altitude oscila entre 150 metros na entrada da unidade e 956 metros no marco sudoeste, próximo ao Pico do Gericinó (MELLO, 2008).

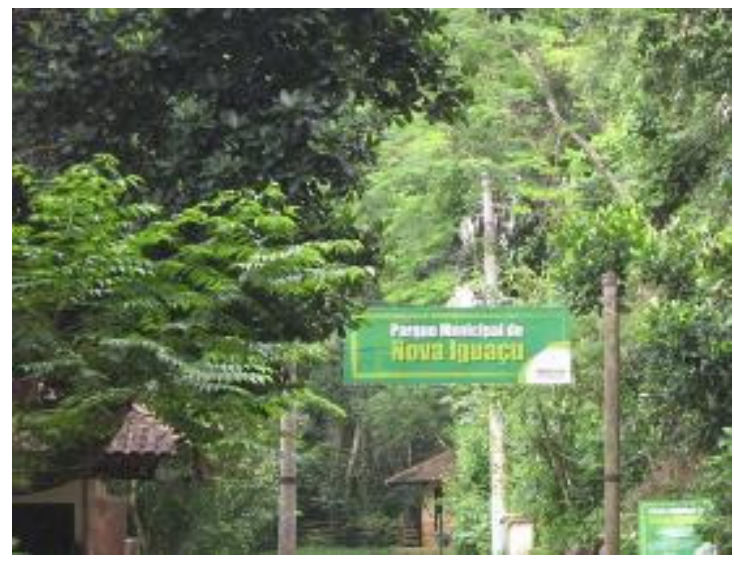

Figura 1: Entrada do PNMNI. Fonte: MACHADO, 2010.

Figure 1: Input to PNMNI. Source: MACHADO, 2010.

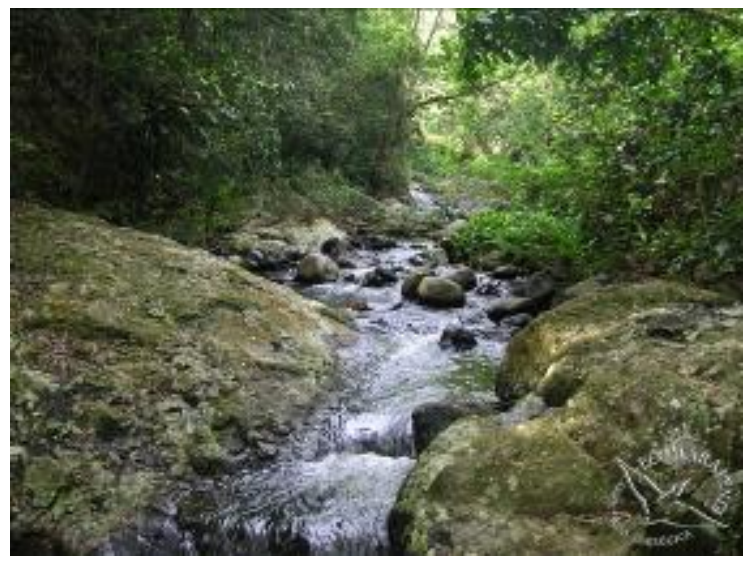

Figura 2: Cachoeira, PNMNI. Fonte: SEMED, 2008.

Figure 2: Rapids, PNMNI. Source: SEMED, 2008.

Está localizado na área conhecida como Gleba Modesto Leal, inserida na parte ocidental da Serra do Madureira, outrora denominada Engenho da Cachoeira, formada pelas antigas Fazendas Dona Eugênia e Fazenda São Felipe, em 1885. É o primeiro Geoparque do Estado do Rio de Janeiro com atributos que contemplam valores ecológicos, culturais e históricos, como o "Casarão" (Figuras 3 e 4), conhecido, outrora, como a sede da Fazenda Dona Eugênia. Essa construção é de valiosa relevância, pois data do século XIX sendo a mais antiga edificação do município. Outros exemplos são as ruínas do clube Dom Felipe, que funcionou até meados da década de 1960, indicando a vocação da área, para o lazer na natureza; e o Quilombo, área de ocupação quilombola perto da pedra da Contenda (NOVA IGUAÇU, 2001).

Cabe destacar ainda os inúmeros locais representativos da história geológica da região que motivaram a descoberta do vulcão de Nova Iguaçu, que se estima estar inativo há 38 milhões de anos, e a inclusão do PNMNI no projeto "Caminhos Geológicos" idealizado pelo Departamento de Recursos Minerais do Estado do Rio de Janeiro - DRM-RJ, com o propósito de trazer a cultura da Geologia para o Estado. Embora a existência do único vulcão brasileiro seja contestada por inúmeros pesquisadores, é 
consenso que o Parque apresenta feições geológicas de especial importância científica e beleza cênica, que representam uma singularidade na geologia da região.

Atualmente, a região da Serra de Madureira destaca-se por ser uma das poucas áreas da Baixada Fluminense que sobrevive à degradação ambiental. Ali se abri-

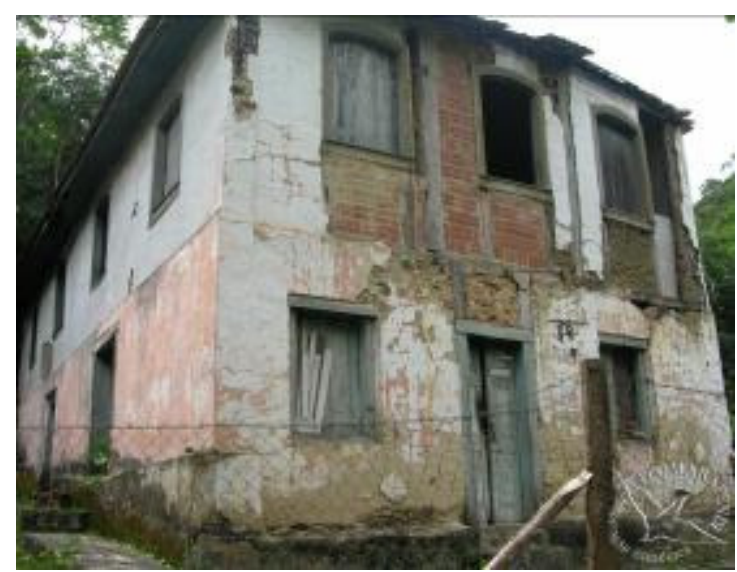

Figura 3: Casarão, PNMNI. Fonte: SEMED, 2008.

Figure 3: Home, PNMNI. Source: SEMED, 2008.

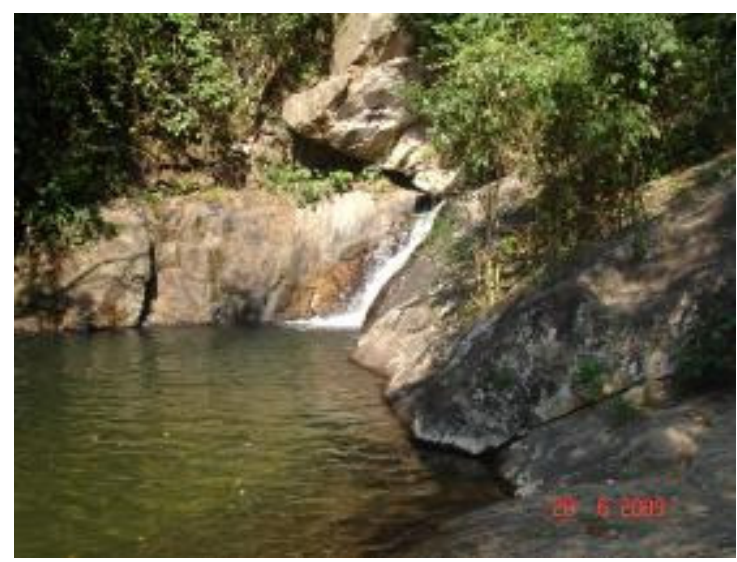

Figura 4: Poço do Casarão, PNMNI. Fonte: MACHADO. 2009.

Figure 4: Well to home, PNMNI. Source: MACHADO, 2009.

gam ainda florestas constituídas com ambientes de diferentes fisionomias vegetais: florestas regeneradas, em ótimo estado de conservação; florestas secundárias em estágio avançado de regeneração; florestas secundárias em estágio médio de regeneração; florestas secundárias em estágio inicial de regeneração; matas ciliares; brejos e capinzais. O PNMNI vem sendo objeto de estudos científicos, o que permite um conhecimento razoável da biodiversidade local.

No Parque se desenvolvem atividades esportivas ligadas à natureza como a prática de rapel, escaladas nos paredões rochosos, e caminhadas por trilhas. Com belas cachoeiras abertas ao público, o parque se configura como ótima opção de lazer na região chegando a receber um efetivo de 3000 visitantes nos finais de semana ensolarados de verão. É também uma ótima opção para trabalhar a consciência ecológica nos alunos da rede de ensino de Nova Iguaçu e municípios vizinhos, com o propósito, conforme destacamos nesta pesquisa, de construir e integrar toda uma rede de apoio ecoturístico ao PNMNI, nele atuando direta ou indiretamente.

Vale à pena ressaltar que é estabelecida uma parceria entre os Municípios de Nova Iguaçu e Mesquita, para uma gestão compartilhada e alternada do Parque. $\mathrm{Na}$ verdade, ele atualmente é administrado pelo Município de Nova Iguaçu, mas com a emancipação de Mesquita, a estrada da Cachoeira, a estrada de acesso e a entrada ficaram situadas no novo município.

O propósito de uma gestão compartilhada e alternada após o processo de emancipação garantiu à cidade de Nova Iguaçu, dentro do plano regional, um modelo de administração moderna e profissional em contraponto com os personalismos en- 
contrados em outros municípios da Baixada Fluminense. A ideia era a de passar uma imagem da conciliação e agregação sem subordinação das cidades vizinhas, respeitando a autonomia destas e convocando-as a serem parceiras (SIMÕES, 2007).

\section{As escolas contempladas}

Em números absolutos, Nova Iguaçu é a cidade da Baixada Fluminense que possui a maior concentração de escolas públicas, reunindo o mais alto percentual de escolas de Ensino Fundamental (NOVA IGUAÇU, 2004). Atualmente, o município apresenta um índice de alfabetização de $80 \%$ da população urbana; a cidade dispõe de 126 escolas municipais. Segundo dados fornecidos pela Secretaria Municipal de Educação de Nova Iguaçu (SEMED - Nova Iguaçu), na Unidade Regional de Governo Centro há 21 escolas.

As escolas que integraram a pesquisa são mostradas na tabela 1 e na figura 2. Elas estão localizadas na Unidade Regional de Governo (URG) Centro, área de influência do Parque Natural Municipal de Nova Iguaçu. Este recorte espacial é determinante para a escolha de cada Unidade Escolar como objeto deste estudo.

Tabela 1: Endereço das Escolas.

Tabela 1: Address of schools.

\begin{tabular}{|c|c|}
\hline E.M. Monteiro Lobato & $\begin{array}{l}\text { Rua Professor Paris } s / n^{\circ}-\text { Centro CEP } 26221 \\
-150\end{array}$ \\
\hline E.M. Julio Rabelo Guimarães & $\begin{array}{l}\text { Rua Dom Henrique no } 230 \text { - Dom Rodrigo CEP } \\
26260-200\end{array}$ \\
\hline E.M.Prof. ${ }^{a}$ Izabel dos S. Soares Mello & $\begin{array}{l}\text { Rua Capitão Edmundo Soares no } 184 \text { - K11 } \\
\text { CEP 26250-440 }\end{array}$ \\
\hline E.M. Prof. ${ }^{\text {a }}$ Venina Corrêa Torres & $\begin{array}{l}\text { Rua João Batista Rodrigues no } 182 \text { - Califór- } \\
\text { nia CEP } 26220 \text { - } 470\end{array}$ \\
\hline E.M. Dr Thibau & $\begin{array}{l}\text { Avenida Abílio Augusto Távora no } 1334 \text { - Bair- } \\
\text { ro da Luz CEP } 26225-320\end{array}$ \\
\hline
\end{tabular}

Fonte: MACHADO, 2011.

Source: MACHADO, 2011. 


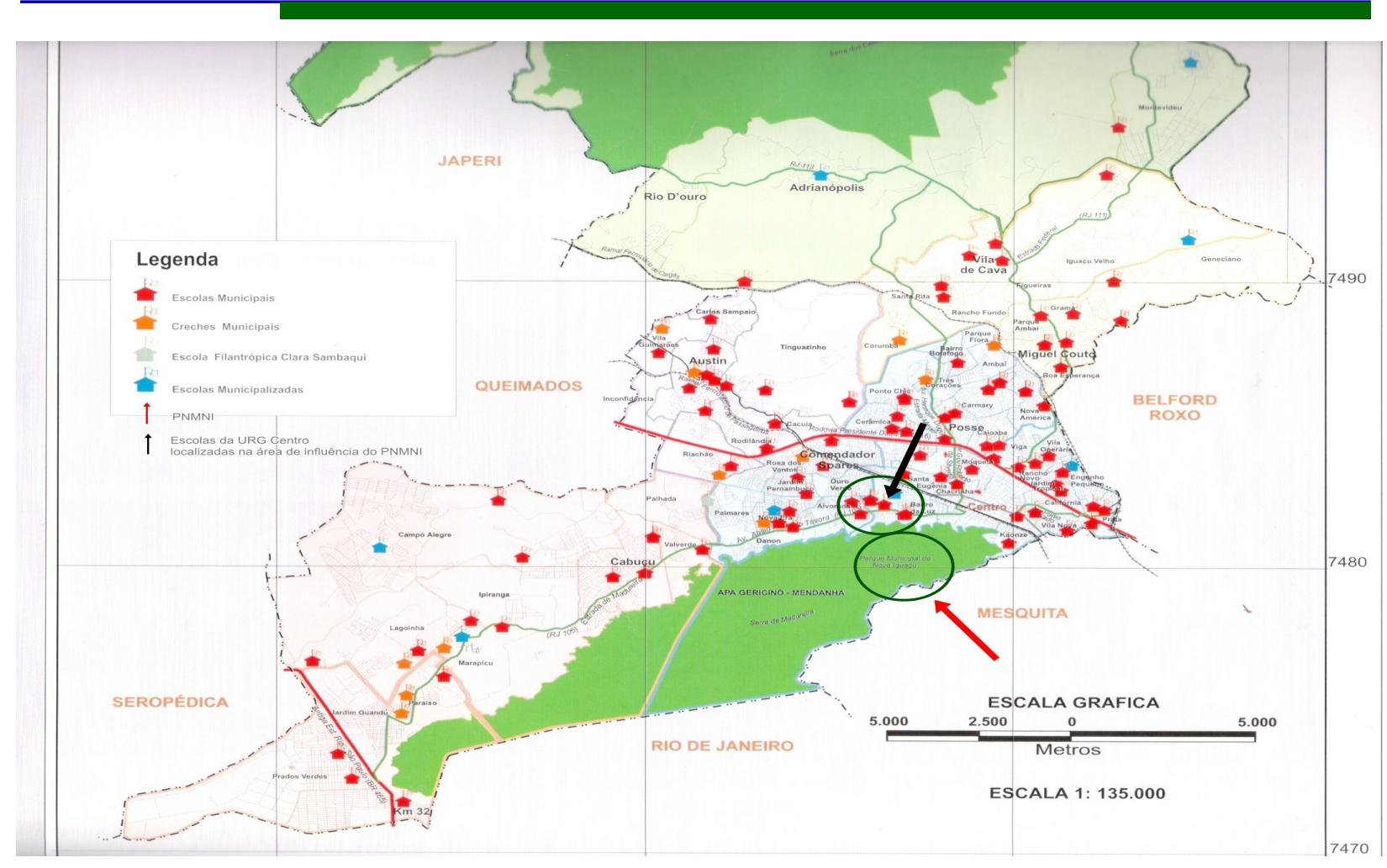

Figura 5: Escolas no Município de Nova Iguaçu.

Fonte: NOVA IGUAÇU, 2004; adaptado por Machado, 2011.

Figure 5: Schools in the city Nova Iguaçu.

Source: NOVA IGUAÇU; adapted by Machado, 2011.

\section{Metodologia}

O principal objetivo desta etapa consistiu em analisar o Plano de Manejo do PNMNI (Figura 6) e avaliar/diagnosticar as práticas educativas, contextualizadas ao tema transversal "Meio Ambiente", desenvolvidas nas escolas localizadas no entorno do Parque.

A avaliação das ações de educação ambiental aconteceu mediante visitas diretas na Secretaria Municipal de Educação de Nova Iguaçu (SEMED), nas escolas e no Parque, aplicação de questionários e entrevista ao gestor do PNMNI.

Os questionários aplicados foram construídos tendo como foco as ações e o espaço de vivência para as práticas de EA e ecoturismo, possibilitando que os entrevistados fornecessem as respostas de forma livre (questionário aberto), o que gerou uma gama de respostas bastante parecidas, em função da realidade comum que permeia as Unidades Escolares.

Os questionários foram direcionados aos diretores e/ou coordenadores políticopedagógicos (CPP), professores do quinto ano do I segmento do Ensino Fundamental e professores do nono ano do II segmento do Ensino Fundamental. Cabe ressaltar que a participação efetiva na pesquisa foi concentrada dentro do universo de quarenta 
e oito questionários respondidos (Tabela 2).

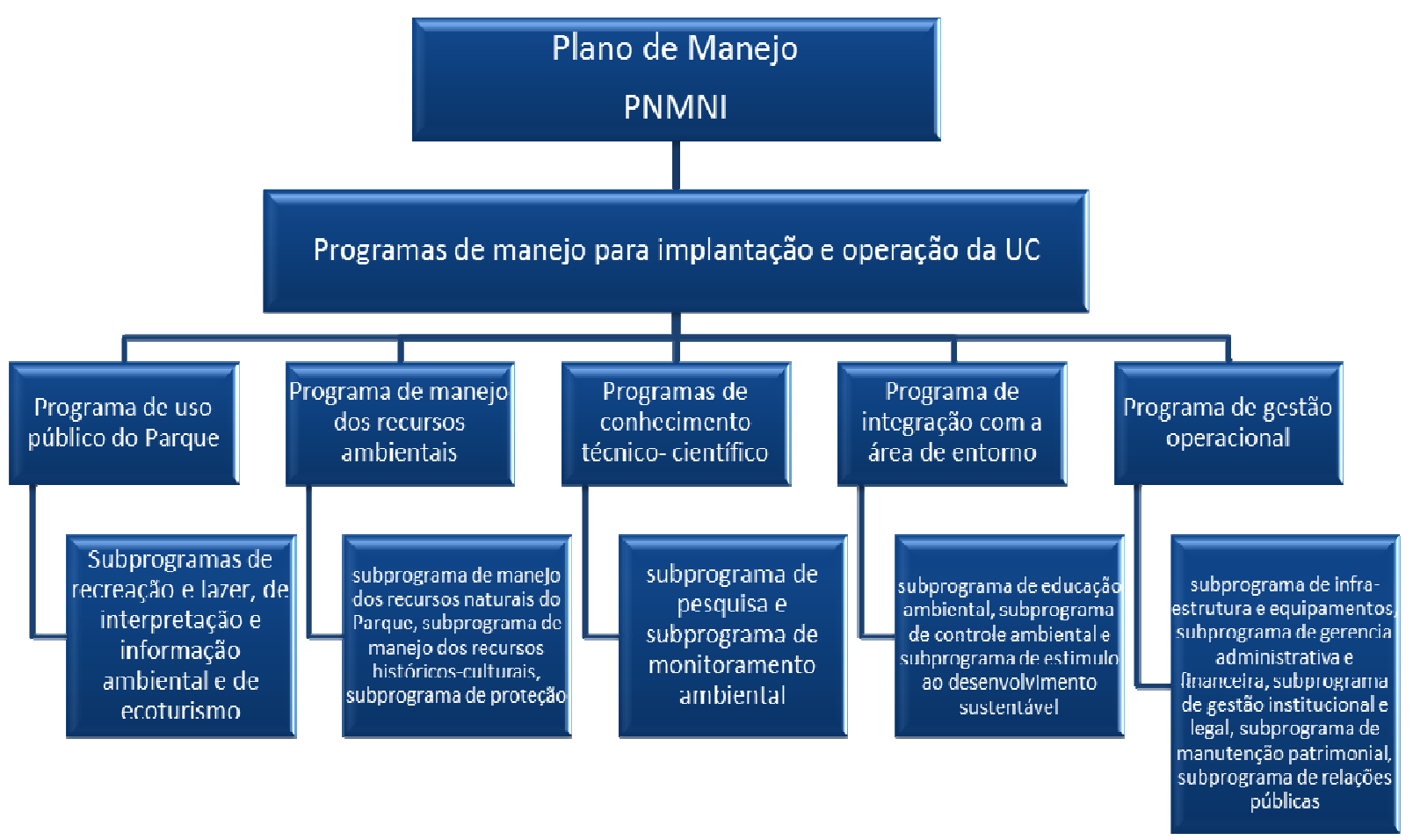

Figura 6: Organograma do Plano de Manejo do PNMNI

Fonte: PCNI, adaptado por MACHADO, 2011.

Figure 6: Chart of the Management Plan of PNMNI Source: PCNI, adapted by MACHADO, 2011.

o primeiro segmento de envolvidos com a temática ambiental pesquisado foi o de diretores e/ou CPPs, que, somados, formam a equipe pedagógica. Esta equipe, responsável pelo direcionamento do trabalho de toda a Unidade Escolar, revela informações acerca da liderança efetiva que exercem no grupo de professores, no que diz respeito ao tratamento da temática ambiental. 
Tabela 2: Educador e a disciplina que leciona.

Table 2: Educator and the discipline that teaches.

\begin{tabular}{|c|c|c|c|c|c|c|c|c|c|c|c|c|}
\hline $\begin{array}{l}\text { Escolas/ } \\
\text { número de } \\
\text { professores } \\
\text { por disciplina }\end{array}$ & $\begin{array}{l}\text { Diretor } \\
\text { e/ou } \\
\text { CPP }\end{array}$ & Cien. & Hist & Geo & $\begin{array}{c}\text { Educ. } \\
\text { Fis. }\end{array}$ & ILPT & Mat. & Ing & Artes & $\begin{array}{l}\text { Ling. } \\
\text { Port. }\end{array}$ & $\begin{array}{l}\text { Integra- } \\
\text { da } \\
\left(5^{\circ} \text { ano }\right. \\
\text { do } 1^{\circ} \underline{ } \\
\text { segmen- }\end{array}$ & $\begin{array}{c}\text { Total de } \\
\text { profs } \\
\text { por } \\
\text { escola }\end{array}$ \\
\hline $\begin{array}{l}\text { Escola Munici- } \\
\text { pal Monteiro } \\
\text { Lobato }\end{array}$ & 1 & 1 & 2 & 5 & 2 & 1 & 1 & 1 & 1 & 1 & 5 & 21 \\
\hline $\begin{array}{c}\text { Escola Munici- } \\
\text { pal Venina } \\
\text { Corrêa Torres }\end{array}$ & 1 & - & 1 & 2 & - & 1 & - & 1 & 1 & 3 & 2 & 12 \\
\hline $\begin{array}{l}\text { Escola Munici- } \\
\text { pal Professora } \\
\text { Isabel dos } \\
\text { Santos Mello }\end{array}$ & 1 & - & - & - & - & - & - & - & - & - & 2 & 3 \\
\hline $\begin{array}{l}\text { Escola Munici- } \\
\text { pal Dr. Thibau }\end{array}$ & 1 & - & - & - & - & - & - & - & - & - & 2 & 3 \\
\hline $\begin{array}{l}\text { Escola Munici- } \\
\text { pal Julio Rabe- } \\
\text { lo Guimarães }\end{array}$ & 1 & 1 & - & 1 & - & 1 & 1 & 1 & - & 1 & 2 & 09 \\
\hline $\begin{array}{l}\text { Total de pro- } \\
\text { fessores por } \\
\text { disciplina }\end{array}$ & 5 & 2 & 3 & 8 & 2 & 3 & 2 & 3 & 2 & 4 & 13 & 48 \\
\hline
\end{tabular}

Fonte: MACHADO, 2011.

Source: MACHADO, 2011.

O segundo conjunto de atores envolvidos foi o de professores. Este grupo lida diretamente com o educando em sala de aula, sendo o viabilizador direto da possibilidade de construção de conhecimentos para seu público.

O terceiro conjunto de atores envolvidos foi representado pela gestão do PNMNI.

As perguntas dos questionários e da entrevista (gestor do PNMNI) buscaram diagnosticar como eram propostas e realizadas estas ações nas escolas pesquisadas e no PNMNI. As análises das respostas apresentaram resultados e reflexões aqui descritas e contribuíram para a construção de um prognóstico, que poderá ser implementado na Rede Municipal de Educação de Nova Iguaçu. O período de acompanhamento das escolas selecionadas correspondeu aos meses de junho a dezembro de 2010.

\section{Resultados}

O ecoturismo aliado à educação ambiental pode contribuir para a formação de alunos mais participativos e sensíveis a ações efetivamente conservacionistas. Contudo, essa realidade não se constitui numa prática exercida, tanto no PNMNI quanto nas escolas analisadas e, mais ainda, sem a existência de conectividade entre ambos, apesar da alta possibilidade de interação. 
O objetivo do Subprograma de Educação Ambiental do PNMNI é bastante nobre, que é o de edificar um Programa de Educação Ambiental nas escolas da região, com vistas à construção de atitudes protecionistas ao ambiente (NOVA IGUAÇU, 2001), entretanto, na prática, o processo é diferente. São realizadas poucas visitas orientadas ao PNMNI com os alunos da Rede Municipal de Educação de Nova Iguaçu (Figura 7).

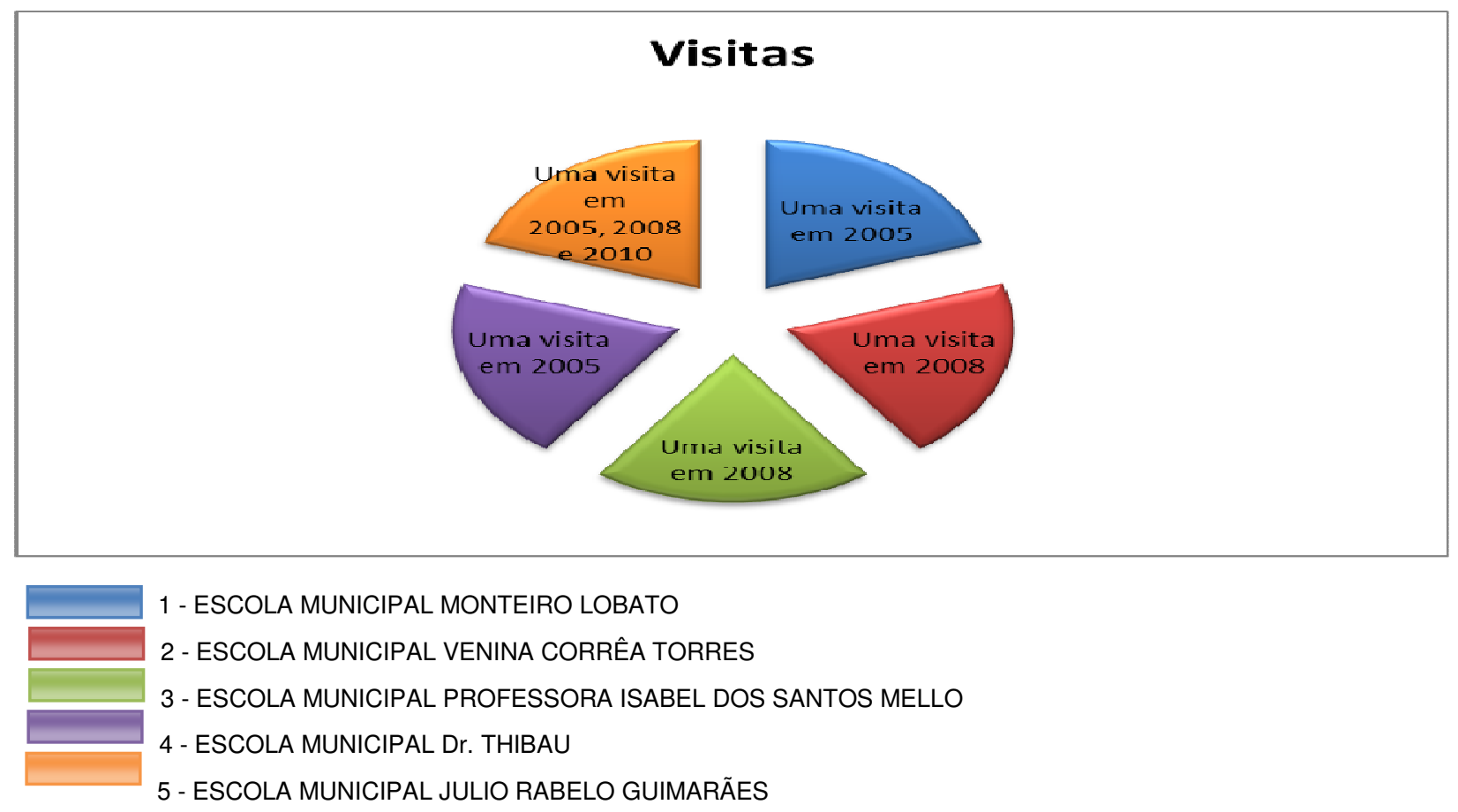

Figura 7 - Periodicidade/ano das visitas ao PNMNI Fonte: MACHADO, 2011.

Figure 7 - Frequency/year of visits to PNMNI Source: MACHADO, 2011.

Segundo Geerdink e Neiman (2010, p. 70):

As atividades de campo podem promover ganhos no que se refere ao aprendizado diferenciado que o aluno recebeu. Ao possuir informações suficientes a respeito da realidade, os estudantes podem pensar de modo crítico sobre fatos e decisões que Ihes são informadas, ampliando sua consciência socioambiental e instigando neles a vontade de mudanças. Os estudos do meio devem estar inclusos no projeto pedagógico das escolas como uma atividade que integra os conhecimentos, faz uma somatória dos aprendizados e permite ao aluno conhecer e amadurecer seus conceitos a respeito de questões e conteúdos trabalhados.

Acreditamos que a prática respaldada em trabalhos de campo deve deixar de ser pontual o que, por consequência, promoveria um maior envolvimento dos alunos com a temática ambiental e estimularia o processo ensino-aprendizagem, tornando-o mais parti- 
cipativo, interessante e próximo ao real e concreto.

Percebemos ao longo da pesquisa que existe no PNMNI uma carência de produção de material com finalidade pedagógica, que muito poderia contribuir para uma aproximação dos educandos com a proposta socioambiental e ecoturística em Nova Iguaçu.

Algumas questões precisam ser avaliadas em relação à estrutura do PNMNI, com o intuito de beneficiar à UC em seus aspectos ambientais propriamente ditos e de facilitar a apropriação de seu patrimônio ambiental por parte de seus alunos frequentadores. Citando alguns destes aspectos, a título de exemplificação, têm-se a contratação de profissionais, a construção de cursos de capacitação, a manutenção de trilhas, o incentivo a práticas ecoturísticas e de inclusão social.

Destarte, a desarticulação entre os atores sociais envolvidos na pesquisa é notória: escola (direção, CPP e professores) e gestão do Parque. Naquela, percebemos que, embora os integrantes estejam localizados, especificamente, dentro do mesmo ambiente, ainda assim, em alguns momentos, apresentam certo descompasso de planejamento e ações.

O pouco ou nenhum tratamento transdisciplinar é outro ponto que chama atenção nesta análise. Ainda não é efetiva a participação de todas as disciplinas no trabalho pedagógico voltado para o ambiente. Para o professor de segundo segmento, mais particularizada se torna a abordagem, relacionada, na maioria das vezes, àquelas disciplinas que tradicionalmente tem o ambiente intrínseco aos seus conteúdos programáticos. É, sem dúvida, uma perda para o aluno, que deixa de ter a oportunidade de receber contribuições oriundas de diversas ciências para a explicação da análise de seu próprio espaço. Esta questão é minorada nas turmas de primeiro segmento, em função do caráter integrador intrínseco a este profissional, único que articula todos os campos do saber.

O profissional de primeiro segmento possui a seu favor o fato de ser ele o único a ministrar todas as disciplinas, o que lhe confere maior facilidade de integrá-las e realizar uma perspectiva de trabalho transdisciplinar. A temática ambiental ganha, neste sentido, a vantagem de ser analisada sob o viés de várias disciplinas, o que é muito enriquecedor para o aluno. Em contrapartida, este profissional não possui a especificidade científica que o docente de segundo segmento adquiriu ao longo de sua formação. Desta forma, por algumas vezes, o professor de primeiro segmento pode não conferir um aprofundamento especifico à temática ambiental.

Com o professor de segundo segmento, esta questão não ocorre, contudo, apenas um seleto grupo de profissionais adota o pertencimento da temática ambiental à sua disciplina. O processo que poderia amenizar este contraste seria a formação continuada, voltada para a necessidade de cada grupo de profissionais.

Percebe-se, ainda, que dentro do universo dos profissionais das escolas pesquisadas, poucos deles haviam participado efetivamente de atividades de campo no PNMNI, apesar de saber da existência deste tipo de evento. Isto significa dizer que tal evento ainda é limitado e restrito a alguns profissionais.

Vídeos com finalidades pedagógicas também são raramente utilizados, e de certa forma, o trabalho ainda revela um caráter um pouco tradicional. Não percebemos a utilização de formas inovadoras, como a informática educativa. Quanto ao Projeto Político Pe- 
dagógico (PPP), alguns profissionais não o conhecem na integra, mas sabem de sua existência e de sua importância para o entrosamento de todo trabalho desenvolvido na unidade escolar (UE).

Chama atenção também, em algumas escolas (E.M. Monteiro Lobato e E.M. Prof. Venina Correa Torres), o fato do grande quantitativo de professores e alunos residir distante da UE, o que pode vir a acarretar uma falta de identificação com o entorno. A escola, vista apenas como um ponto de chegada ou partida, não gera para seus frequentadores uma identidade com o lugar. Todo o Patrimônio Ambiental que existe neste entorno traz uma ausência de significados para seus alunos e professores (Figura 8). Não há valorização e sequer conhecimento do ambiente natural ali intrínseco.

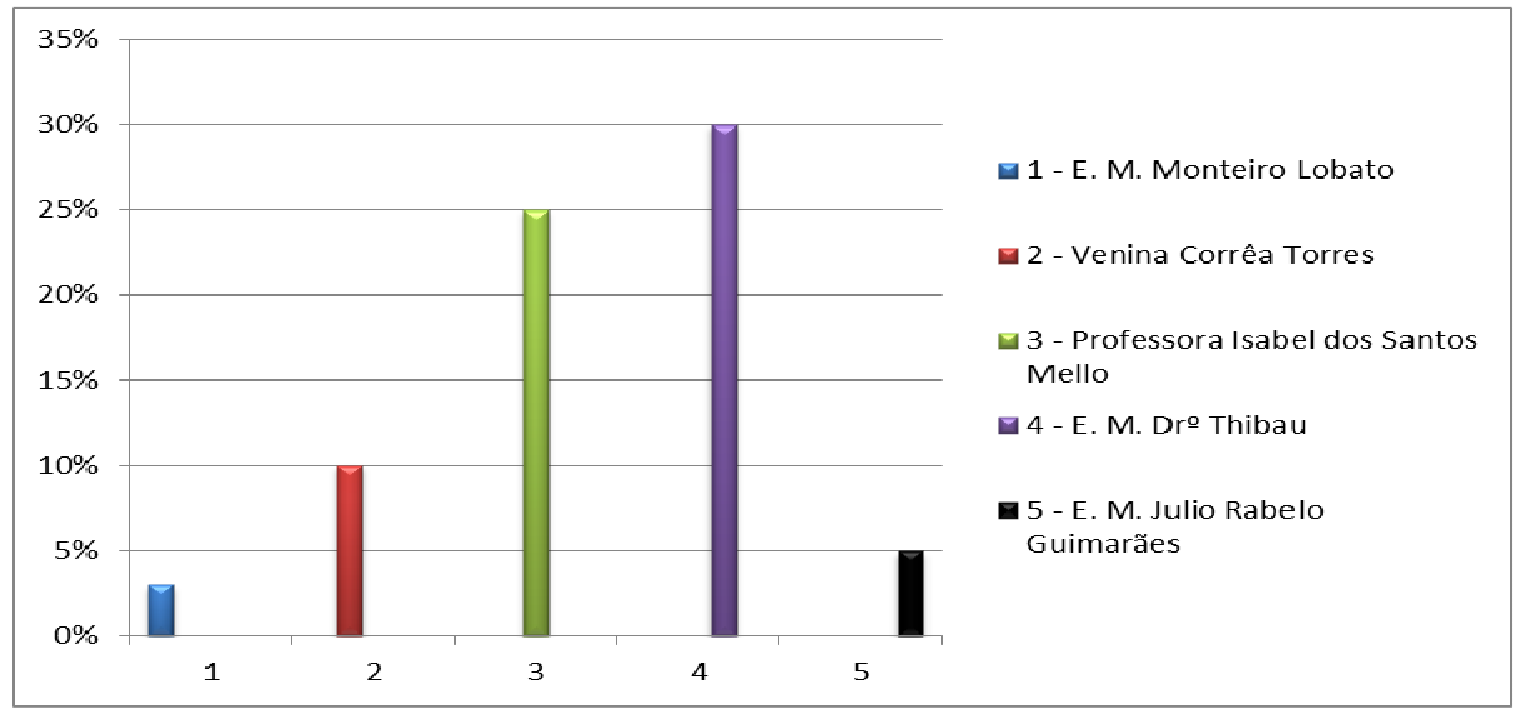

Figura 8: Quantitativo de professores que residem no entorno da escola Fonte: MACHADO, 2011.

Figure 8: Quantitative teachers residing around the school Source: MACHADO, 2011.

Diante desta realidade, é interessante que a escola e a administração do Parque promovam ações mais integradoras, onde haja incentivo de seus profissionais a utilizarem metodologias mais dinâmicas de trabalho, respaldadas na interdisciplinaridade, como: atividades de campo, recursos informáticos e meios atrativos de sensibilização.

É necessário, também, que espaços promotores de embasamento teórico conceitual acerca da temática ambiental sejam disponibilizados de forma ampla, com a respectiva orientação, suporte e acompanhamento das ações das escolas, bem como a avaliação dos resultados alcançados (BRASIL, 1998)

Quanto à gestão do PNMNI, é importante, inicialmente, uma maior articulação entre a secretaria responsável pela sua gestão - Secretaria de Meio Ambiente e Agricultura, e a secretaria responsável pela gestão das unidades escolares - a Secretaria Municipal de Educação. Ambas precisam coordenar um planejamento que contemple uma finalidade comum, um objetivo único a ser alcançado, para então formular as ações que possibilitarão alcançar a meta proposta. Esta finalidade comum é o desenvolvimento deste aluno - cidadão, que veja na sua cidade, Nova Iguaçu, na sua comunidade, no seu entorno, o 
Patrimônio Ambiental que lhe é imediato e que também está sob sua responsabilidade.

Assim como as escolas, o PNMNI precisa estar preparado para receber este público, e ainda, levar seu conhecimento até ele. Para tanto, é fundamental criar um elo entre o PNMNI e as escolas; construir um material de apoio adequado para dar suporte às ações que são desenvolvidas. Cabe a gestão do Parque incentivar as escolas a realizarem visitas com o suporte adequado. Já as escolas precisam inserir no planejamento, nas ações previstas no PPP, as visitas, as práticas ecoturísticas no PNMNI, embora as atividades sociais e estudos associando ecoturismo e educação ambiental sejam reduzidos.

Nesta perspectiva, ao estimular visitas ao PNMNI, a escola na figura da equipe pedagógica e, principalmente, professores, além de propor uma simples caminhada, pode explorar diversos temas, como: localização e enquadramento geográfico, memorial descritivo geral da UC, processo histórico de ocupação, Patrimônio Histórico e Natural, aspectos institucionais e legais, caracterização geobiofísica do Parque e caracterização socioeconômica.

Embora o foco esteja, sobremaneira, nas escolas, a gestão do Parque pode colaborar na efetivação das propostas de ações integradoras de educação ambiental formal e ecoturismo. Pode, também, fornecer toda a gama de informações sobre o manejo e gerenciamento do PNMNI.

Para a realidade iguaçuana, conhecer e compreender o campo do ecoturismo e da educação ambiental justifica-se como uma necessidade primordial para o desenvolvimento de iniciativas e intervenções, de diagnóstico ambiental e de gerenciamento e manejo do PNMNI. Por isso, é fundamental uma maior preocupação com a formação de atores sociais qualificados, capazes de atuar diretamente na animação de processos educacionais que envolvam, de forma ativa, as pessoas na defesa do ambiente e nas ações pela recuperação e melhoria das condições de vida.

Destarte, para que tais ações possam ser materializadas, algumas medidas devem ser construídas coletivamente, como a formação de parcerias para a obtenção de recursos (material e financeiro) fundamentais no ordenamento do ecoturismo local, de modo profissional; o desenvolvimento do ecoturismo, como forma de gerar renda para os moradores da região; o aumento do número de escolas e de alunos envolvidos em atividades de EA; a ampliação do número de visitas programadas ao Parque realizadas pelas escolas da Rede Municipal de Educação de Nova Iguaçu, principalmente, aquelas localizadas na área de influência do PNMNI; a identificação de temas e a produção de material educativo pertinente à região retratada nesta pesquisa; a busca de intercambio e apoio interinstitucional para as atividades de EA; e a criação de cursos de capacitação de multiplicadores.

\section{Propostas integradoras}

Uma proposta de ações integradoras de educação ambiental formal e ecoturismo orienta os atores sociais envolvidos a definirem as práticas político-pedagógicas que meIhor atendam às suas necessidades. Podem oferecer opções de lazer e recreação controlados, em consonância com as premissas básicas para o desenvolvimento do ecoturismo, além de promover mudanças e respostas aos desafios ambientais contemporâneos para o Município de Nova Iguaçu. 
Uma das questões aqui levantadas e discutidas é a preocupação com a capacitação do educador e, por conseguinte, com a formação do educando que, ao final dos seus anos de escolaridade esteja apto a interagir com o seu entorno imediato, representado pelo PNMNI. É a formação do aluno que, após ter vivenciado ativamente o processo de educação ambiental ao longo de sua formação, pode fazer parte de uma comunidade pronta para integrar toda uma rede de apoio ecoturístico ao PNMNI, nele atuar direta ou indiretamente e, ao mesmo tempo, usufruir do lazer na natureza.

É emergencial, portanto, que este aluno, que muito brevemente será um ator social, se aproprie da correta percepção que envolve o ambiente e a educação ambiental. Para tanto, é interessante o conhecimento espacial e transdisciplinar dos aspectos do meio físico-biótico e socioeconômico do Parque Natural Municipal de Nova Iguaçu como subsídio fundamental às propostas educativas e ecoturísticas. Assim, vale à pena oportunizar: a construção de projetos, programas, ações conjuntas envolvendo universidades, SEMED, SEMAM e Gestores das UCs do município; divulgação e conhecimento do Plano de Manejo do PNMNI; ações efetivas de capacitação do público-alvo proposto, envolvendo todos os temas abordados nesta pesquisa (PCNs, PNLD, PM, Ecoturismo...) em associação a EA; uso da Internet via construção de sites ou aprimoramento do conteúdo de páginas já existentes, referentes às UCs e práticas de EA no município.

Propomos que iniciativas e perspectivas para a Rede Municipal de Educação de Nova Iguaçu sejam materializadas na construção de um curso de capacitação para professores, de acordo com o seguinte planejamento: apresentação do objetivo da capacitação; sensibilização do grupo pela temática; estabelecimento do local de realização; duração do curso; conteúdos trabalhados nos encontros; recursos audiovisuais; por quem será ministrado; referencial teórico apostilado; sugestões de trabalho prático com o aluno e a comunidade; estratégia de continuidade da proposta, pois as ações de EA devem ser gradativas, contínuas e diárias.

Neste sentido, tal proposta envolveria as mesmas cinco escolas acompanhadas, pelo fato de partir de uma realidade já bastante conhecida. Estas escolas seriam alvos de um programa de capacitação voltado para suas equipes pedagógicas e professores, articulado através de encontros presenciais abordando as seguintes questões:

=> construção de conhecimentos contextualizados à temática ambiental: caráter conceitual da EA e ecoturismo; reconhecimento das áreas de proteção ambiental do município de Nova Iguaçu, principalmente as que estão próximas as UEs selecionadas;

$=>$ tratamento da temática através avaliação da problemática ambiental de cada Unidade Escolar e entorno;

=> culminância, com apresentação para a comunidade escolar e do entorno, dos resultados alcançados por cada escola;

Após a capacitação, a escola pode tratar da temática com mais propriedade, pois o ambiente natural tão importante e presente no entorno das escolas se transformará em fonte de conhecimento a ser construído e explorado pelo alunado.

Cabe ressaltar que o universo de escolas envolvidas nesta proposta pode ser ampliado, posteriormente, através da sugestão para a formação de uma rede, onde todas as escolas do município teriam voz e visibilidade, baseadas em capacitações na temática ambiental, apresentações e trocas de experiências dos trabalhos realizados ao longo do 
ano letivo ou em períodos pré-determinados. O professor de cada escola levará para este momento as práticas desenvolvidas, às inquietudes, e as perspectivas para o futuro.

O ambiente não será contemplado somente como um tema gerador ou uma proposta pontual, mas como um tema transversal, de interfaces com diferentes ciências/ disciplinas/conteúdos e de tratamento por todas as áreas do conhecimento. Nesta perspectiva, as ações desenvolvidas em todo o ano letivo, ganham relevância e espaço para o diálogo pelo caráter de urgência social e de abrangência local, regional e global, que instrumentalizam a comunidade escolar e do entorno no trato às questões ambientais locais.

Para tanto, caberia, uma proposta de acompanhamento, de formação continuada, onde todos os passos seriam valorizados para a melhor participação e interação entre os diferentes atores sociais e suas respectivas ações (individuais ou coletivas; pública ou privada), respaldadas em autoavaliações e autoajustes pertinentes a todo processo pedagógico e interdisciplinar: alternativo, infindo, gradativo e dinâmico para a sensibilização ecológica e mudanças de atitudes.

\section{Considerações Finais}

Ao analisarmos ambas as realidades - escolas e Parque - nos debruçamos sobre algumas constatações, e os resultados obtidos nesta pesquisa apontam-nos algumas proposições. Acerca das escolas, nosso processo investigativo revelou-nos que documentos valiosos, como os PCN's, que norteiam as ações pedagógicas, ainda não são referenciais em muitas escolas da Rede Municipal de Educação de Nova Iguaçu, o que pode representar um entrave para essas práticas. Além disso, detectamos dificuldades de diversas naturezas, que vão desde a falta de tempo dos professores e da equipe pedagógica para o simples preparo e/ou revisão de seu arcabouço intelectual acerca da temática; até a falta de um suporte material adequado para a realização de atividades de contato com o ambiente (os trabalhos de campo). E ainda, as comunidades locais pertencentes às escolas do entorno do PNMNI muitas vezes não tem nesta área protegida o referencial ambiental local para as práticas de EA e ecoturismo, o que nos obrigou a pensar em uma proposta que contemplasse esta etapa tão iniciática, que seria a percepção de seu próprio entorno.

Já sobre o PNMNI, identificamos outras dificuldades. Inicialmente, o Plano de Manejo, documento basilar na gestão do Parque é pouco conhecido e a consecução dos objetivos dos subprogramas de ecoturismo e educação ambiental não foi constatado durante as análises desenvolvidas através da presente pesquisa. Observamos ainda a presença de dificuldades para a promoção da divulgação dos pontos notáveis da referida UC e para o envolvimento da comunidade local que, por ser conhecedora da região, muito poderia contribuir na descoberta de novas atrações ecológicas que pudessem integrar roteiros de ecoturismo. Relembramos que o envolvimento da população local é fundamental na prática ecoturística.

Esforços de naturezas diversas precisam ser implementados com o propósito de atender as demandas propostas pelos PCN's e pelo Plano de Manejo do PNMNI. Neste, esta realidade ainda é modesta; já nas escolas selecionadas, ainda verificamos o processo de adaptação pelo qual passam, em se tratando de se adequarem às proposições 
contidas nos PCN's. Além isso, elas necessitam da implantação efetiva de um programa de EA que realmente as atenda, no tocante a construção de hábitos e atitudes de respeito e proteção aos recursos naturais e culturais do Parque e da região como um todo.

Neste sentido, ratificamos o caráter emergencial do aprofundamento da temática ambiental junto aos atores que compõem esta proposta de união entre educação ambiental e ecoturismo, com visas ao estabelecimento de uma nova dinâmica ambiental que agregue valores à prática do turismo e mudança de comportamento em relação ao ambiente. Alcançar estes atores significa qualificá-los de formas específicas, acordadas as suas respectivas ações. O gestor do Parque, o educador (de forma continuada), o diretor e o Coordenador Político Pedagógico precisam ser levados à reflexão para que possam, então, proporcionar a sensibilização e formação do educando das escolas da área do entorno do PNMNI.

Por estarmos imersos nesta realidade (e em particular na realidade das escolas) propomos aqui um conjunto de ações que, pela nossa vivência, acreditamos ser viáveis no contexto do nosso âmbito de estudo. Indubitavelmente, estas ações não podem ser isoladas, elas precisam constituir um conjunto sistêmico no sentido de alcançar uma mudança frente aos recursos naturais existentes no PNMNI. Inicialmente nele, pois conforme expomos ao longo da pesquisa, a mudança de atitudes é ampliada às escalas cada vez maiores de atuação e inserção dos indivíduos.

Consideramos que as possibilidades de aplicação dos propósitos da Educação Ambiental nas práticas ecoturísticas tendo como cenário o PNMNI são bastante promissoras. A partir da ampla requalificação dos atores sociais envolvidos em projetos de EA, serão maximizados os impactos positivos, acarretando a melhor distribuição dos benefícios dele decorrentes e levando a uma maior proteção ambiental.

A sociedade sustentável não é para nós um discurso longínquo e com pouca aplicabilidade prática. Ao contrário, encontra no município de Nova Iguaçu a possibilidade real de reunir os diversos atores capazes de influenciar positivamente a fração da sociedade mais receptiva à aquisição do conhecimento - os alunos; e aqueles desejosos de mudanças que agreguem valor às suas experiências de vida - os habitantes do entorno da UC.

A ideia de trazer a eles novas reflexões e mais do que isso, uma sistematização das ações oriundas destas novas perspectivas é tarefa passível de realização que, acreditamos, possa ter resultados em um prazo de tempo que não erraríamos em chamar de breve. A escola, na figura do educador, a partir das habilidades e competências desenvolvidas nos cursos de capacitação, dará um novo enfoque ao trato do tema ambiente, além de estimular e colaborar na execução das práticas de EA que agucem a sensibilidade dos cidadãos iguaçuanos para reconhecer e fomentar ações com bases sustentáveis. O PNMNI, na figura do seu gestor, recepcionará as ações oriundas das unidades escolares, e proporcionará a elas um novo arcabouço infraestrutural, capaz de maximizar os resultados destas ações para os educandos e para a sociedade local. 


\section{Referências Bibliográficas}

BRASIL. Ministério do Meio Ambiente. SNUC: Sistema Nacional de Unidades de Conservação. Brasília: MMA, 2000.

BRASIL. Lei $n^{\circ} 9795$ de 27 de abril de 1999. Dispõe sobre a educação ambiental, institui a política nacional de educação ambiental e dá outras providências. Diário Oficial [da] República Federativa do Brasil, Brasília, 27 abr.1999.

BRASIL. Ministério da Educação. Parâmetros Curriculares Nacionais: Geografia. Brasília: MEC, 1998.

BRASIL. Lei de Diretrizes e Bases da Educação Nacional. Brasília, Senado Federal, 1997.

CABRAL, N. R. A. J.; SOUZA, M. P. Área de proteção ambiental: planejamento e gestão de paisagens protegidas. São Carlos: Rima. 2002.

CADEI, M.S. Educação Ambiental e Agenda 21 Escolar: formando elos de cidadania. Rio de Janeiro: CECIERJ, 2010.

CALLAI, H.C. O ensino da Geografia: recortes espaciais para análise. In: CASTROGIOVAN$\mathrm{NI}$, N.O. et.al. Geografia em sala de aula: prática e reflexões. Porto Alegre: UFRGS/AGB, 2003.

CORIOLANO, L.N.M.T (org.). Turismo comunitário e responsabilidade sócio-ambiental. EDUECE: Ceará , 2003.

COSTA, N.M.C. da. Ecoturismo: abordagens e perspectivas Geográficas. In: COSTA, N. M. C. da; NEIMAN, Z.; COSTA, V.C. da (orgs). Pelas Trilhas do Ecoturismo. São Carlos: Rima, 2008.

COSTA, N. M. C. da; COSTA, V.C. da. Turismo e Meio ambiente. CECIERJ: Rio de Janeiro. 2009.

DIAS, G.F. Educação Ambiental: princípios e práticas. São Paulo: Gaia, 2000.

GEERDINK; S. NEIMAN, Z. A educação ambiental pelo turismo. In: Turismo e Meio Ambiente no Brasil. NEIMAN, Z; RABINOVICI, A (Orgs). Barueri: Ed. Manole. 1ª edição. 2010, pp.63-83.

LEONARDI, M.L.A. Educação Ambiental e teorias econômicas: primeiras aproximações. In: ROMEIRO, A.R. et.al. Economia do Meio Ambiente: teorias, políticas e a gestão de espaços regionais. Campinas: EMBRAPA/ UNICAMP, 1997.

MACHADO, M. L. F. Ecoturismo e Educação Ambiental no contexto da Baixada Fluminense: um diagnóstico das escolas do entorno do Parque Natural Municipal de Nova Iguaçu - RJ. 2011. 143f. Dissertação (Mestrado em Geografia) - Instituto de Geografia, Universidade do Estado do Rio de Janeiro, Rio de Janeiro, 2011.

MACHADO, M. L. F. As ações de Educação Ambiental no contexto da Baixada Fluminense: o exemplo da Entidade Ambientalista e Práticas Sustentáveis Onda Verde (Tinguá - Nova Iguaçu / RJ). 2007. 156f. Monografia (Especialização em Políticas Territoriais no Estado do Rio de Janeiro) - Instituto de Geografia, Universidade do Estado do Rio de Janeiro, Rio de Janeiro, 2007. 
MELLO, F.A.P. Ordenamento da malha de trilhas como subsídio ao zoneamento ecoturístico e manejo da visitação no Parque Natural Municipal de Nova Iguaçu - RJ. 2008. 192f. Dissertação (Mestrado em Geografia) - Instituto de Geografia, Universidade do Estado do Rio de Janeiro, Rio de Janeiro, 2008.

MENDONÇA, R.; NEIMAN, Z. Ecoturismo: Discurso, desejo e realidade. In: Ambiente, Educação e Ecoturismo. NEIMAN, Z. (Org.). Barueri: Ed. Manole, 1ª edição, 2002, pp.159-176.

NOVA IGUAÇU (RJ). Atlas Escolar Geográfico da Cidade de Nova Iguaçu. Nova Iguaçu: A Prefeitura, 2004.

NOVA IGUAÇU (RJ). Secretaria Municipal de Urbanismo e Meio Ambiente. Plano de Manejo do Parque Natural Municipal de Nova Iguaçu. Nova Iguaçu: A Prefeitura, 2001. 3 v.

SANTOS. M. A natureza do espaço: técnica e tempo, razão e emoção. São Paulo: Edusp, 2004.

SIMÕES, M. R. A Cidade Estilhaçada: reestruturação Econômica e Emancipações Municipais na Baixada Fluminense. Entorno: Mesquita, 2007.

Marcia Luiza Figueiredo Machado: Secretaria Municipal de Educação de Nova Iguaçu, Nova Iguaçu, RJ, Brasil.

Email: marcialuizafm@terra.com.br

Link para o currículo Lattes: http://lattes.cnpq.br/6986236447556623

Nadja Maria Castilho da Costa: Universidade do Estado do Rio de Janeiro, Rio de Janeiro, RJ, Brasil.

Email: nadjacastilho@oi.com.br

Link para o currículo: http://lattes.cnpq.br/8646672305430213

Data de submissão: 26 de maio de 2012

Data de recebimento de correções: 11 de dezembro de 2012

Data do aceite: 11 de dezembro de 2012

Avaliado anonimamente 